\title{
СУЩНОСТЬ И РАЗВИТИЕ ОСОЗНАННОСТИ: НАУЧНЫЕ И РЕЛИГИОЗНЫЕ ПРЕДСТАВЛЕНИЯ
}

\section{ESSENCE AND DEVELOPMENT OF AWARENESS: SCIENTIFIC AND RELIGIOUS REPRESENTATIONS}

\section{A. Nepomnyashchy} E. Haybulina

Summary: The purpose of this article - to give the overview of approaches to a question of awareness in religious practice, psychological consultation and modern science. In the text it is shown that the quality of awareness is a subject of practice of Buddhists from the moment of origin of this religion that is reflected in the level of everyday life practicing and directly in meditation. The awareness plays an important role in spiritual life of Christians, being realized in a trezvleniye concept, and in sufis spiritual life which have a special practice of concentration on the spiritual purposes. The purpose of this practice is the condition of the fana or self-destruction in God. J. Krishnamurti and K. Wilbur emphasize that the awareness can stop process of an attribution and bring to detection of true quality of understanding. The awareness plays an important role in psycho-therapeutic practice, allowing to be more free from determinism. Approaches in studying of awareness from the point of view of artificial intelligence are described. Approaches to a question of gradation of awareness are shown. The description of the approach to a question of awareness offered by V.M. Allakhverdov according to whom the awareness is necessary to eliminate the contradictions arising during decision making is given. In the article questions of that why understanding when the decision is made for some time before his understanding as the awareness in meditation when no decisions are made that happens to awareness in a condition of a conscious dream of the practicing Buddhist is possible is necessary are raised. Possible answers on these questions from the positions of integral vision received on the basis of the application of models of the person and his consciousness developed in religions of pure experience are offered.

Keywords: person, awareness, consciousness, models, religion, representations, subjective experience, witness, triad structures.

\author{
Непомнящий Анатолий Владимирович \\ Д.п.н., профессор, Южный федеральный университет, \\ Таганрог \\ pibgtsu@mail.ru \\ Хайбулина Эльвира Ильясовна \\ Старший преподаватель, Санкт-Петербургский \\ институт культуры \\ msgosh12@yandex.ru
}

Аннотация: Цель настоящей статьи - дать обзор подходов к вопросу осознанности в религиозной практике, психологическом консультировании и современной науке. В тексте показано, что качество осознанности является предметом практики буддистов с момента возникновения данного течения, что отражено на уровне повседневной жизни практикующих и непосредственно в медитации. Важную роль осознанность играет в духовной жизни христиан, воплощаясь в концепте трезвления, и в духовной жизни суфиев, у которых существует специальная практика сосредоточения на духовных целях. Целью этой практики является состояние фана или самоуничтожение в Боге. Дж. Кришнамурти и К. Уилбер подчеркивают, что осознанность может остановить процесс атрибутирования и привести к обнаружения чистого качества осознания. Осознанность играет важную роль в психотреапевтической практике, позволяя быть более свободным от детерминизма. Описаны подходы в изучении осознанности с точки зрения искусственного интеллекта. Показаны подходы к вопросу о градации осознанности. Дано описание подхода к вопросу осознанности, предложенного В.М. Аллахвердовым, согласно которому осознанность необходима для того, чтобы устранять возникающие в ходе принятия решений противоречия. В статье ставятся вопросы 0 том, зачем нужно осознание, когда решение принимается за некоторое время до его осознания, как возможна осознанность в медитации, когда никакие решения не принимаются, что происходит с осознанностью в состоянии осознанного сновидения практикующего буддиста. Предложены варианты ответов на эти вопросы с позиции интегрального видения, полученные на основе применения моделей человека и его сознания, разработанных в религиях чистого опыта.

Ключевые слова: человек, осознанность, сознание, модели, религия, представления, субъективный опыт, наблюдатель, тринитарные структуры.

ют неоднозначность дефиниции понятия более высокого уровня - «человек», которому, собственно, и присуща эта характеристика его активности как субъекта своей жизнедеятельности.

Феномен осознанности известен людям с древности вековедения, касающимся сущности человека, его жизнедеятельности и развития. Дефиниции этого понятия не однозначны, что закономерно, поскольку отобража-

онятие «осознанность» бытия личности и индивида, как носителя в себе индивидуальности, 
и используется в различных религиозных практиках в качестве инструмента для постижения самим человеком своей духовной природы и постижения истины. Из этих практик известно, что, хотя осознанность присутствует всегда, она проявляет себя в разной мере. Для сохранения осознанности требуются усилия, но ее качество можно развивать. В то же время, в повседневной жизни обычного человека, не относящегося к адептам религиозного опыта или к практикующим психологам высокой квалификации, она не всегда явно присутствует и, порой, даже считается им не всегда полезной. Но во всех школах самосовершенствования вопрос о развитии осознанности звучит совсем в другом ключе: без развития качества осознанности интегральное, целостное развитие личности, индивида и человека вообще, как субъекта (управителя) своего жизненного пути, - невозможно. Все это и определяет актуальность исследования этого человеческого качества, в связи с чем в науке и существует проблема такой дефиниции этого понятия, которая соответствовала бы задаче развития личности и существующему в науке стремлению к однозначности.

Последнее - самое трудное в исполнении, поскольку наука существует в пространстве объективного [20], а осознанность в сути своей относится именно к субъективным качествам личности, исследованием которых и занимается религия, в системе которой проблем с определением, что такое осознанность - нет, поскольку это определение передается не объективными средствами того, или иного текста, а средствами субъект-субъектного взаимодействия в системе учитель-ученик, в процессе которого искомая дефиниция передается в виде интегрального образа сути, а не её явлений, как это происходит в науке.

Разработке этой научной проблемы посвящено достаточно много работ, в части которых осознанность в опыте повседневной жизни, в психологической практике и в религиозном опыте на своем базовом уровне видится имманентно присущей мировосприятию, миропониманию и ощущению течения жизни [2], представляясь первичной и неоспоримой данностью, навыком, свойственным почти любому человеку, что делает возможным её функционирование и в процессах психотерапии, где она понимается как качество присутствия внимания в моменте времени «здесь и сейчас» и выступает ключевым ресурсом для процесса исцеления и души, и тела [27].

Многие исследователи фиксируют именно этот факт, что осознанность свойственна личности, сосредоточенной на проживании ситуации «здесь и сейчас» и переживающей полноту текущего опыта. Осознанность не является следствием интеллектуального знания человека о себе и о внешнем мире, но связана с полноценным проживанием именно текущего момента, не сводимого исключительно к рациональному мировосприятию или стимул-реактивным поведенческим схемам. Именно поэтому возникает «свобода, несмотря на детерминизм» $[1]$.

Считается, что осознанность связывается с состоянием фиксации присутствия чего-либо в сознании в большей мере, чем с природой самих объектов восприятия. K.W. Brown и R.M. Ryan определяют осознанность как фоновый радар сознания, фиксирующий события внутренней и внешней среды [28]. Эта метафора представляется весьма удачной, что будет показано ниже, хотя она и не избавляет от необходимости определения смысла, вкладываемого автором в понятие «фоновый радар». Но этой метафорой исследователи подчеркивают, что осознанность обнаруживается в любой деятельности человека и проживается в повседневном опыте как чистое знание о том, что актуально происходит вокруг и внутри нас в настоящий момент восприятия [28]. Благодаря этому качеству возможно погружение сознания человека в состояние «здесь и сейчас», где производится сознательный выбор, позволяющий регулировать возникающие при этом психические явления [16].

Однозначному научному определению осознанности, на наш взгляд, мешают, прежде всего, методологические погрешности: не соответствующая задаче парадигма, на которую, порой неосознанно, опираются многие исследователи, и отсутствие интегрального видения проблемы. Так, например, есть мнение, что в научном дискурсе есть только три основных подхода к изучению осознанности [16]. К ним автор этого представления относит следующие.

1. Осознанность как результат работы биологической системы. Ее можно смоделировать как любую физическую систему.

Этот подход на самом деле есть не более чем попытка пролонгировать жизнь идеи о том, что тело - есть субстрат (производитель) психики, а сознание является функцией мозга. В этом подходе и соответствующих представлениях осуществляется опора на парадигму времен И. Ньютона, когда в науке считалось, что масса вселенной постоянна, что возможно только в том случае, если во вселенной кроме вещества, из которого, в частности, состоит биологическое тело человека, никаких субстанций (энергии, информации, времени и пр.) - нет. Таким образом, упоминание этого подхода в качестве имеющего право на жизнь с позиции современной науки - некорректно.

2. Хотя осознанность является результатом работы биологической системы, моделирование может только создать эффект осознанности в поведении, но это не будет идентично внутреннему содержанию - не будет означать наличие осознанности. Здесь видим ту же самую ошибку - опору на па- 
радигму времен младенческого материализма. Следовательно, и эту исследовательскую позицию, как и первую, нельзя даже рассматривать в качестве возможного подхода к исследованию осознанности.

3. Осознание не может быть смоделировано вовсе и не подлежит научному изучению и концептуализации.

Эта позиция также не может предлагаться в качестве отправной точки какого-либо исследования, поскольку любой фрагмент действительности может быть смоделирован. Вопрос заключается в другом: «Можно ли создать текстовую или символьную, проблемно ориентированную модель осознанности, пригодную для решения рассматриваемой проблемы?». Что касается научного изучения, то его также никто не может запретить. Прямое изучение субъективного пространства наукой действительно невозможно в силу отсутствия измерительных средств, но косвенное изучение сути по её отражениям и отображениям никто отменить не может, поскольку тогда пришлось бы отменить и психологию. Концептуализацию также никто отменить не может, поскольку человеку свойственно передавать информацию не только в образах, но и в тексте, и в символах. Именно последние средства отображения знания всегда и строятся на основе той или иной идеи, т.е. концепции.

Итак, мы видим, что, помимо неадекватной научной парадигмы, причиной существования приведенных подходов к исследованию осознанности является еще и отсутствие интегрального, четырехсекторного видения [20], из-за чего изучение субъективного пространства мира объявляется невозможным вообще, поскольку считается, что познание мира возможно только объективными средствами, что лишает права на жизнь не только психологию, но и все науки, на неё опирающиеся. И все это потому, что для классической науки источник осознания, так и не стал предметом исследования (в силу его отрицания ею), и в этом смысле не может быть направлен сам на себя $[19,24]$.

В качестве выхода из этой ситуации осознанность понимается также, как осведомленность - осознание чеголибо, чувствительность к моментальным содержаниям сознания [24]. В компьютерной метафоре человека она может рассматриваться как результат выполнения вычислительных операций, и в этой трактовке способность осуществлять вычисления приравнивается к осознанию [16]. Осознанность положительно коррелирует с ясностью сознания, состоянием осведомленности, поиском нового, но не имеет в ряде представлений корреляций с рефлексией, которая понимается как процесс, позволяющий субъекту направлять внимание на происходящее в собственном внутреннем мире или в мире вокруг, таким образом, чтобы осмысливать и регулировать поведение. Как отмечают K.W. Brown и R.M. Ryan, отличительным свойством осознанности является то, что операции производятся «на», а не «посредством» содержания сознания [28]. Такое утверждение можно предложить, только опираясь на все ту же идею о том, что сознание не является в человеке иерархически высшей управляющей системой. Здесь немедленно возникают два вопроса: «Кто производит эти операции «на» сознании, игнорируя его содержание?»; «А разве механизм осознанности дан человеку не для того, чтобы осмысливать и регулировать свое поведение на качественно ином, более высоком уровне взаимодействия с миром?» Эти вопросы авторы, по-видимому, оставляют без ответа, что также указывает на несоответствие поставленной задаче парадигмы и методологии, которые ими используются для решения проблемы осознанности.

Если смотреть на функционирование осознанности, обнаруживается, что более ярко осознанность проявляется при высвечивании ранее неосознаваемых процессов сознания, т.е. их переноса в сферу осознаваемого, что вовсе не означает прекращение протекания последних, поскольку информационный объем неосознаваемого несоизмеримо больше объема того, что осознается личностью. По мнению В.М. Аллахвердова, использующего для иллюстрации осознанности компьютерную метафору, в то время как основные вычислительные процессы осуществляются в сфере неосознаваемого, механизм осознанности необходим для устранения противоречий, которые не могут быть решены без участия личности как субъекта, что возможно благодаря тому, что все неосознаваемые процессы некогда были в поле осознания и имеют имманентную тенденцию - становится таковыми вновь [24]. Однако осознанность здесь ставится под вопрос, при условии, что основания принимаемого решения подготавливаются в неосознаваемом и выдаются как уже готовый результат [1]. В то же время возникает вопрос, как возможно осознанное наблюдение, не включающее явного решения задач, в условиях медитации, когда остается только процесс чистого созерцания [4]? Как обрабатывается информация в таком особом режиме работы сознания? Еще один пример неординарного проявления осознанности - осознаваемые сновидения, в процессе которых, при активной работе неосознаваемых сил, возникает очаг осознанности, который может не только поддерживать чувство Я, но может быть усилен до медитативного состояния, когда без пробуждения практикующий сохраняет яркую осознанность [18].

Эти, и подобные им умозаключения и представления, возникшие в системе науки, имеют характер фиксации факта, явления, но не вносят желаемого вклада в разъяснение сущности данного качества личности и человека, 
в связи с чем и возникает множество открытых вопросов. Отсюда естественно вытекает необходимость обращения к истокам психологических знаний, поступающих в науку от истинной религии как носителя методологии восстановления связи с Богом, в которой осознанности придается огромное практическое и теоретическое значение.

Здесь под истинной религией не имеются ввиду конфессиональные социальные институты догматического плана, цель которых не исследование и разъяснение, а убеждение прихожан в необходимости примкнуть к той или иной системе представлений, консолидирующих приверженцев какой-либо догматики. Нам целесообразно знакомство с теми представлениями об осознанности, которые сформировались в религиях «чистого опыта», поскольку в них отображены не столько результаты стороннего наблюдения, сколько результаты собственного практического самоисследования, многократно подтвержденные ранее и постоянно подтверждающиеся ныне адептами многих школ в буддизме, даосизме, суфизме, конфуцианстве, мистическом христианстве и в других религиях чистого опыта. Под чистым опытом в данной классификационной характеристике указанных религий понимается отсутствие ментальных и интеллектуальных спекуляций о чем-либо, касающемся предмета рассмотрения и исследования. Примат теории над практикой, часто существующий в системе гуманитарных наук, в них отсутствует, что никоим образом не означает отсутствие теоретических оснований религиозного опыта вообще. Речь идет о балансе знания и бытия, без которого возникновение понимания невозможно [23]. Об этом, в частности, говорит нам и теория Абхидхаммы (ранний буддизм) [9], в которой были разработаны проблемно ориентированные модели сознания, сохраняющие и поныне свою актуальность, в том числе, и для решения поставленной здесь задачи.

Буддисты всегда видели необходимость осознавать события внутреннего и внешнего мира с целью достижения предельного состояния осознанности (нирвана), выступающего в качестве главного механизма на пути к избавлению от страданий. Благодаря данному качеству практикующий в настоящее время, как и сотни лет назад, может реализовать «сати» или «сампаджанну» - памятование через осознанность, предполагающее удержание внимания на всех происходящих внешних и внутренних событиях в текущий момент времени. Объектами, с которыми при этом работает осознанность, являются любые содержания сознания, связанные с восприятием, мышлением, воображением, обнаруживаемые в практиках сосредоточения, самадхи и безмятежного наблюдения [12]. В сутте «О всех влечениях» осознание выступает в качестве основы для развития усердия, восторга, успокоения, сосредоточения, безмятежного наблюдения, которые являются необходимым элементом практик [11].
В другом тексте в отношении использования качества осознанности в монашеской жизни указывается следующее: «сохраняй памятование и осознавание. Когда подходишь и когда отходишь, действуй осознанно. Когда смотришь прямо и смотришь в сторону, действуй осознанно» [11].

В качестве аналога осознанности в христианстве можно рассмотреть понятие трезвления, что в контексте данной философии имеет значение рассудительности, свободы от обмана, иллюзий [7]. В труде Иоанна Лествичника указано следующее: «Внимай себе трезвенно после молитвы, и увидишь, что толпы бесов, побежденных нами, стараются после молитвы осквернить нас нечистыми мечтаниями. Итак, сядь и наблюдай, и ты увидишь обыкших похищать начатки душевного делания.» Это может быть расценено как обращение к особого рода внимательности к своему состоянию, характеризующейся полнотой осознания. Там же указано: «Хотя во всем нужно нам иметь великое трезвление, но прежде прочего должно в этом отношении наиболее быть разумно внимательными»; «Все бесы покушаются сначала помрачить наш ум, а потом уже внушают то, что хотят; ибо если ум не смежит очей своих, то сокровище наше не будет похищено» [10, с. 28].

Осознанность играет значимую роль в аскетических практиках, т.к. предполагает своевременное отслеживание процессов, происходящих в сознании, позволяя добиться успехов в борьбе с пороками. Отсутствие осознанности, как можно предположить, связывается с помрачением ума, что влечет за собой исчезновение «трезвенного внимания», рассуждения, сознания и появление нерассуждения и слепоты ума [10]. Трезвление подразумевает «не частную добродетель, а трезвление во всем, когда человек хранит себя от всякого дела, слова и помышления, неугодного Богу» [10, с. 98]. Это качество пронизывает все добродетели. Осознанность здесь проявляется в чистоте души и тела, в сохранении её как во сне, так и наяву, в нейтральном отношении к объектам мира. Из приведенного видно, что практика осознанности в христианстве, так же, как и в буддизме, предполагает внимательность по отношению не столько к формам, сколько к их содержаниям.

В суфизме существует отдельно обозначаемая система техник, называемая «муракаба», составляющая основу «учения о трезвости» багдадской школы мистицизма [25], предполагающая, что практикующий будет сохранять неугасающую сосредоточенность на религиозных заповедях и духовных целях. При полном отрешении от восприятия внешнего мира осознанность позволяет достичь постоянного видения Бога «оком» разума в состоянии, называемом «фана», предполагающем уничтожение иллюзии самости в Боге. Здесь также встречается понятие трезвого взгляда, позволяющего отказаться от 
мирских привязанностей [14].

Дж. Кришнамурти отмечает, что осознанность предполагает остановку процесса атрибутирования: «есть дерево, есть слово, реакция на дерево, которая представляет собой цензора, «я», приходящее из прошлого; и затем существует вопрос: могу ли я спастись от всей этой суматохи, от всех мучений? Если данный вопрос задает само «я», оно благодаря ему увековечивает самого себя. И вот, осознав это, оно не задает вопроса! Когда налицо осознание, понимание того, что подразумевает данный вопрос, задать его нельзя» [8].

Осознание предшествует размышлениям и предполагает чистое созерцание процессов, оно присутствует всегда. К. Уилбер описывает это так: «мне не нужно пытаться вызвать к жизни осознание. Мне не нужно стараться войти в это состояние. Для этого не требуется ровным счетом никаких усилий. Я просто замечаю, что оно уже существует» [19, с.215]. Но здесь опять возникает старый вопрос: «А “Я", это кто?». Ответить на него в тексте, не прибегая к методу моделирования, невозможно, в связи с чем, для показа варианта решения поставленной проблемы и предложения ответов на приведенные выше вопросы, к этому методу и обратимся, применяя методологию постнеклассической науки, использующей все виды знания (обыденное, объективно-научное, философское и эзотерическое), наиболее ярко выраженную в методологии интегрального видения, предложенной К. Уилбером [20]. При этом, исходные предпосылки к решению проблемы заключаются в следующем.

1. Необходимо учитывать существование мировых универсалий, в частности, - закона третьей силы, который следует из нелокальности квантовых эффектов и говорит о том, что нет никакой возможности организовать взаимодействие любых двух цельностей мироздания без участия в этом взаимодействии третьей силы [17]. Тринитарные структуры пронизывают все наше существование [3]. Даже сам Творец этого мира проявляется тринитарно как сила созидания, сила сохранения созданного и сила растворения созданного [5]. Следовательно, предположение о том, что человек проявляется дуально, как взаимодействие таких его ипостасей, как думающий и делающий [22], неверно уже в силу того, что любой процесс управления также тринитарен по своей структуре и представляет собой организацию, регуляцию и контроль. Таким образом в человеке есть и третья ипостась - человек наблюдающий, контролирующий происходящее, а забывают о нем потому, что его действие в человеке непрерывно и столь естественно, что не требует от личности никаких усилий. Именно поэтому К. Уилбер и пишет, что для вхождения в состояние осознания «... не требуется ровным счетом никаких усилий. Я просто замечаю, что оно уже существует» [19].

2. Ответ на другой вопрос о том, кто или что в человеке является этим наблюдателем, осознающим все происходящее, будем искать, учитывая другую мировую универсалию - принцип иерархии мироустройства, игнорировать который без риска «заблудиться в трех соснах» невозможно. Из него следует, что человек, в целом, и его сознание, как и все в мире, имеет иерархическую структуру. Именно поэтому нельзя утверждать, что в состоянии осознания «... операции производятся «на», а не «посредством» содержания сознания [28]. Операции «на» осуществляется только внешним наблюдателем (третьей силой) - сознанием более высокого уровня, нежели человеческой. И этот феномен безусловно существует, поскольку «Субъективное Я» (сознание) отдельного индивида всегда входит в «Субъективное Мы» (коллективное сознание) того иерархического уровня, в который он входит как составляющий элемент [20]. В самом же индивиде нет другого наблюдателя кроме его сознания, о котором буддисты говорят, что это то, из чего все происходит. Вопрос заключается в том, с какого иерархического уровня сознания в конкретном случае ведется осознанное наблюдение. Значит, в соответствии с этой универсалией должны выбираться многоуровневые проблемно-ориентированные модели человека и его сознания, обладающие достаточным объяснительным потенциалом. Здесь нам будет достаточно использовать наиболее общие, не детализированные модели, своего рода «карты» (в терминологии К. Уилбера) большого масштаба, сродни тем, что применялись не столь давно в авиации для ориентировки с большой высоты. Эти модели апробированы многовековой практикой и разработаны в религиях чистого опыта.

В качестве модели иерархической структуры человека целесообразно использовать семиуровневую модель, предложенную более века назад братом-мирянином мистического ордена Розенкрейцеров М. Генделем в его фундаментальном труде «Космоконцепция Розенкрейцеров [6]. В несколько упрощенном, проблемно ориентированном виде, она может быть представлена в виде иерархической семиуровневой структуры, в которой три верхних уровня представляют собой Триединый неделимый Дух (Божественный Дух, человеческий дух и жизненный дух) и являет собой, согласно сведениям, лежащим в основе всех религий и опирающейся на их основу «вечной» философии, «То», неизрекаемое в слове, с чем во многих религиях Востока и отождествляется сам человек и что в христианстве называется «Святой троицей» (Бог отец, Бог сын, Бог Дух святой) или искрой Божьей внутри каждого из нас. Эта Искра Бога внутри каждого из нас и есть своего рода ядро человеческой 
индивидуальности, обретающей свою исключительность вследствие уникальности своего опыта в процессе бесконечных изменений (смен) своих форм проявления. Именно это движение - от простых форм ко всё более сложным, называемое эволюцией, и является по сути нелинейным процессом бесконечного развития каждой индивидуальности. И в познании себя посредством проявленного и непроявленного бытия человек не может «пропустить» какую-либо ступень лестницы восхождения к Богу в себе. Не достигнув совершенства в малом, невозможно быть совершенным в большем.

4-7 уровни проявления Духа в модели М. Генделя (тело мысли, тело желаний жизненное тело и биологическое тело) являются по своему изначальному назначению проводниками его воли. И, если человек находится в состоянии «счастья» - соединения всех частей (уровней) в единую систему, объединенную общей целью, эта функция проводников выполняется безукоризненно, как безукоризненно части, входящие в устройство телевизора, осуществляют одна за другой усиление и преобразование входного сигнала до максимальной проявленности в форме звука и изображения на экране. Но, фундаментальное отличие живого существа от технического средства заключается в том, что «живые» проводники в системе «человек» обладают невыясненной до сих пор степенью сложности, собственным сознанием соответствующего уровня и способностью к самоорганизации, самоконтролю и саморегуляции, т.е. к самоуправлению. Объединившись в ещё более сложную подсистему человека по имени «личность», они тяготеют к реализации этих своих функций и возможностей, зачастую не очень обращая внимание на сигналы индивидуальности и сигналы друг друга. В таком состоянии (отсутствия «счастья» и осознания происходящего) человек и совершает множество проб и ошибок, забыв о Боге в себе, позволив своему эго вытеснить Бога в «тень» вместе с другими своими «хорошими» и «плохими» составляющими и свойствами, с которыми эго на данный момент не готово встретиться, поговорить и включить в себя [24]. Именно поэтому на Востоке великие Учители всегда призывали каждого индивида отказаться от иллюзии личности как главного управленца в системе «человек» и направить все усилия на установление устойчивого контакта с Богом в себе.

Само понятие «иеро архия» в качестве своего основного смыслового значения имеет «управление сверху». Это означает, что соблюдение этого принципа в структуре человека, находящегося в состоянии счастья, автоматически означает, что личность принимает свой Божественный Дух в качестве главного, высшего по уровню иерархии сознания, контролирующего наблюдателя и главного управленца. При этом достигается состояние полной осознанности бытия, поскольку Дух, будучи Искрой Бога, можно сказать, используя физическую метафору, является его голографической копией, обладающей всеми присущими Богу бесконечными возможностями, почему и говорится, что Бог создал человека по образу и подобию своему.

Такое состояние весьма трудно достижимо, поскольку множество людей, находясь в процессе своего эволюционного развития на уровне «разума страдания» не допускают и мысли, что они являются манифестациями Бога и могут пребывать всегда и всюду в состоянии «разума праздника», к чему призывают все религии чистого опыта. Главной причиной этого является отсутствие правильного самоотождествления.

Научная парадигма в виде закона сохранения массы, осознанно или нет, но еще присутствует в сознании многих жителей Земли, которые вследствие этого отождествляет свое «Я» со своим инструментом - биологическим телом. И это отождествление присуще не только обывателям, но и представителям разных уровней науки (вплоть до академиков), находящихся под магией этой формулировки закона сохранения, сформулированного не один век назад в рамках классической науки. При таком отождествлении самости, существование других, иерархически высших структур в человеке вытесняется личностью в «тень», в неосознаваемое ею, куда вслед за Богом отправляется и процесс осознавания. Это не означает, что само «наблюдение» исчезает. Бог в каждом из нас по-прежнему осуществляет свои функции, но их результат не видим для личности, поскольку она отрицает само его существование.

Таким образом, совершенствование процесса отождествления самости у личности отображается и в совершенствовании её осознанности. По мере развития своего мировосприятия личность начинает «доставать из тени» на свет своего осознаваемого восприятия и знания последовательно уровень за уровнем. Признание существования жизненного тела и его исследование приводит к тому, что личность становится способной осознанно регулировать свое энергетическое состояние и, как следствие, состояние здоровья своего биологического тела. Теперь она может осознанно наблюдать процессы, происходящие в этих телах. Принятие идеи о существовании «тела желаний» и исследование его функций приводит к дальнейшему расширению осознаваемого в сознании личности, которая высветила из тени теперь уже три уровня из своей телесной иерархии и, говоря: «Я хочу», демонстрирует окружающим свое отождествление с телом желаний и т.д. И так, поднимаясь в своем самоотождествлении с одного уровня внутренней иерархии на другой, личность, в конце концов, доходит до своей границы. Дальше только Дух, и, пересекая эту границу, личность (как управленец в системе «индивид») «растворяется» в Духе, передавая ему властные полномочия. Бог в человеке выходит из тени. Это состояние 
личности называется в ряде религиозных школ «вибхути» (пепел) [26] и считается очень высоким достижением в развитии человека, поскольку иллюзия личности, этого инструмента индивидуальности, больше не закрывает собой истину. В культуре наших предков это состояние называлось «вера» - ведание $\mathrm{Pa}$ - пребывание в Боге.

Для иллюстрации ключевых этапов в развитии осознанности можно использовать и иерархическую модель собственно человеческого сознания в целом, в которой феномен сознания рассматривается в плане актуализации активности составляющих его внутренней структуры, классифицируемой по признаку доступности той или иной области (зоны) сознания для осознания и волевых актов [9].

Указанное подразделение на зоны сделано на основе признака дифференциации сознания и положения о том, что сознание колеблется между двумя предельными состояниями - «дифференциации» (одна особь на этом уровне принципиально отличается от другой) и «однородности» (нет никаких существенных различий между двумя особями). В этом плане периферическое сознание наиболее дифференцировано, что и позволило выдвинуть идею существования эго и соответствующих этой идее концепций. Под дифференциацией здесь подразумевается возможность наблюдения множества различий (от особи к особи), т.е. индивидуальных характеристик, проявляющихся в процессе существования личности. Именно применительно к этому уровню структуры сознания возможно введение и использование таких понятий, как личность и эго, а также рефлексия соответствующих качеств и характеристик, в том числе эмоциональных, чувственных, и волевых. Активность этой зоны сознания проявляется в бодрствующем состоянии человека, в способности совершать осознаваемые волевые акты. Внешняя информация, содержащаяся в периферической зоне сознания, поступает к человеку преимущественно через посредничество сенсорных систем, доступна для волевого вспоминания. Ограниченность информационного объема этой зоны, что и обуславливает её дифференциацию от периферических сознаний других особей, обусловлена ограниченностью полосы пропускания сигналов сенсорными системами человека. Функции осознаваемого наблюдателя в этой зоне реализуются с помощью ума, как проводника сигналов Духа и фокусировщика внимания. В процессе осознания задействованы также такие структурные составляющие тела ума, как физический разум (фрагментатор мира) и интеллект, обеспечивающий мышление и логические операции в системе языка.

Субпериферическая зона располагается за порогом способности обычного человека к волевому вспоминанию, ее активность у среднестатистического человека проявляется в виде «ночного» сознания - сознания спя- щего человека или находящегося под гипнотическим воздействием. Активность сенсорных систем в этой области сознания минимальна, поскольку они не в состоянии пропустить через свои каналы столь большой объём информации. Степень дифференциации сознания (от субъекта к субъекту) в этой зоне значительно меньше в силу того, что наше, дифференцированное от других Эго, занимает в этой зоне сознания ничтожно малую часть и, кроме того, ряд факторов (движущих сил) сознания, в частности волевых, здесь не активны. Это огромное информационное вместилище, с одной стороны, питающее периферическую зону, с другой - поглощающее из нее все то, что прошло апперцепцию и относится к опыту, сформированному на периферии - в сфере осознаваемых отношений с Миром. Вот почему многие исследователи сознания искали пути волевого смещения фокуса внимания и осознанной рефлексии из периферической зоны в субпериферическую для осознаваемого исследования и использования грандиозных возможностей сознания человека как управляющей системы. Такая техника на востоке была известна с незапамятных времен и относилась к одной из техник медитации - осознаваемого входа в континуальные потоки самосознания (определение В.В. Налимова) [13]. В ряде традиций эта техника называется осознаваемым сновидением или работой со сновидческим телом [18]. Трудности освоения этих техник заключаются в том, что наблюдатель, функции которого выполняет «тело мысли» (ментальный план человека), должен присутствовать в процессе этих сновидений, лишаясь возможности внетелесного опыта, восстанавливающего и развивающего его состояние [6]. Насильственное, неестественное освоение этих техник, например, с помощью средств электронной техники или психоделических препаратов, чревато весьма тяжелыми последствиями для всех уровней структуры личности.

Сублиминальная зона - зона максимальной однородности. Здесь индивидуальные различия не могут быть проявлены в силу бесконечной информационной ёмкости этой части сознания - одна бесконечность не может отличаться от другой. Это означает, что перемещение фокуса внимания и осознанности в эту зону дает возможность исследователю на практике осознать единство с Богом, с миром и весь мир в себе: поскольку индивидуальные различия отсутствуют, концепция эго теряет свою основу и эго исчезает как таковое (состояние вибхути). Осознаваемые вход в эту зону и выход из нее обратно на периферию позволяет получить осмысленное знание всего обо всем, поэтому человек, достигший этих возможностей изменения состояния своего сознания и называется на востоке Буддой - Познавшим. На сегодняшний день известен только один безопасный путь к достижению такого уровня подготовки - нирваны, который и относится к главным открытиям Будды Гаутамы - восьмеричный путь, в основе которого лежит три фундаментальных принципа: Мудрость (Правильное Воз- 
зрение и Правильная Решимость), Нравственность (Правильная речь, Правильное Поведение и Правильный Образ Жизни) и Сосредоточение (Правильное Усилие, Правильная Собранность Разума и Правильное Сосредоточение). Все другие пути в область сублиминального сознания, ведущие «в обход" решения задачи этического, нравственного и интеллектуального самовоспитания, связаны, как правило, с процессом смерти индивида в прямом и переносном смыслах, поэтому Анагарика Говинда [9] называет сублиминальное сознание сознанием «мертвого» человека, т.е. либо сознанием человека, простившегося со своим конкретным биологическим телом навсегда, либо сознанием человека, пребывающего в состоянии нирваны, т.е. временно оставившего своё тело, предварительно «выключив» его, но держа его под контролем. Для внешнего наблюдателя, не имеющего специальной подготовки в сфере субъективного опыта, отличие этих состояний неуловимо, поэтому известный русский писатель был заживо похоронен родственниками, принявшими его нирвану за кончину.

Изменение состояния сознания, при котором активная, произвольная компонента его внимания (ментальный наблюдатель) пересекает границу между субпериферической и сублиминальной зонами сознания вызывает эффект, который в художественной литературе часто описывается фразой «вся жизнь промелькнула у него перед глазами». Эту фразу нужно понимать буквально, что было доказано множественными экспериментальными результатами, полученными в пограничных состояниях человека (между жизнью и смертью) с неопределенным заранее исходом. Дальнейшее погружение в сублиминальную зону без потери осознанности происходящего дает возможность «промелькнуть перед глазами» и другим - прошлым жизням, как это было, например, описано в повести Г. Гессе «Сиддхартха» и в целом ряде научных исследований (Р. Монро, М. Ньютон и мн. др.).

Анализ рассмотренных моделей человека и его сознания, разработанных в сфере субъективного опыта, приводит к следующим выводам.

Главная цель человека - познание истины, что необходимо для результативного управления любым видом деятельности. Если под истиной понимать ви́дение и понимание актуального состояния мира, которое изменяется каждое мгновенье, поскольку и Бог и весь мир находятся в постоянном творчестве, то она для обычного человека, а тем более для его личности, - непознаваема. Это маяк, стоящий на скале. Все корабли к нему стремятся, но ни один не достигает, зато те, которые следуют его сигналам, приходят в порт назначения. Так и личность, стремящаяся к истине, неизбежно достигает своих жизненных целей, поскольку человек является манифестацией Бога, а стало быть, несёт эту истину в себе, но не видит этого, не имея осознанного контакта с главным Наблюдателем, со своей Божественной сущностью, часто с позиции своей личности даже отказываясь верить в само её существование.

Собственно, именно отсюда и возникает, с одной стороны, задача постоянного самообразования и самосовершенствования, поскольку достижение состояния осознания хотя бы той конкретной ситуации, которой человек хочет управлять, возможно только при достижении достаточного знания и опыта, относящихся к этой ситуации (принцип Эшби). С другой стороны, это достигается только в состоянии осознанности самих процессов обретения нового опыта и восприятия новых знаний, т.е. мы имеем издревле известный вариант «змеи кусающей себя за хвост», который отображался в философской проблеме взаимоотношения бытия и сознания. Принимая гипотезу о том, что «бытие определяет сознание» (речь идет о периферийном сознании), мы движемся к расширению последнего через совершенствование бытия. Принимая обратное, мы концентрируемся на задаче расширения сознания через интенсификацию внутренней работы, что приводит к совершенствованию и нашего бытия. У кольцевых структур нет ни начала, ни конца. Все тотально взаимозависимо.

Уйти от задачи повышения осознанности путем расширения периферийного сознания мы никуда не можем, если хотим стать субъектом (управителем) своего жизненного пути, на котором судьба и карма выстраивает нам для проживания (обучения) персональный событийный ряд, собирая в нем для ускорения развития и других, подобных нам существ.

Главная стратегия развития осознанности - стараться целиком присутствовать своим сознанием в текущем моменте текущей ситуации, соблюдая при этом этику общения с другими и этику общения с самим собой. Это известный принцип «быть здесь и сейчас», практике которого учили все Великие издревле. В современности ничего не изменилось: других, более эффективных стратегий, - нет. Тактических путей было открыто достаточно много. Эти пути можно сгруппировать в два направления (подхода): дифференцированные практики и интегральные практики. Под первыми мы понимаем практики, ориентированные на развитие определенного качества в человеке или отдельной части его структуры, например: развитие умственных способностей; развитие отдельных телесных качеств (скоростных, силовых, выносливости) и т.п. Применение вторых практик предусматривает интегральное развитие человека как цельности, без допущения своего рода перекосов, возникающих, например, при отставании развития левого или правого полушарий мозга. Нарушение в человеке принципа равновеликости всегда затормаживает процесс расширения периферийного сознания. Так сама 
наша Природа заботится о том, чтобы негармонично развитый человек не смог нанести себе много вреда, получив преждевременно бо́льшие возможности.

Если изучать направления йоги, известные со времен Патанджали, мы увидим во всех них именно интегральный характер, что следует уже из самого названия системы - «йога», т.е. «единение», стирание границ, которое и начинается с постижения состояний «яма» (этика общения с другими) и «нияма» (этика общения с самим собой). В то же время для западного исследователя эти направления могут восприниматься принципиально отличными друг от друга и относиться больше к дифференциальным практикам, что связано с самим характером логического (научного, рационального) мышления западного человека.
Не отрицая ни одного из этих подходов, можно извлечь из них много преимуществ. По такому пути пошли многие, в частности авторы работы «Практика интегральной жизни» [21], где, для вхождения в проблему и ускорения понимания, вся практика дифференцируется на четыре модуля: работа с телом, душой, духом и «тенью». Со временем, по мере расширения своего сознания, практикующий начинает понимать, что в работе с каждым конкретным модулем неизбежно задействуется вся структура «человек», и все её структурные составляющие постоянно подают практикующему знаки для обеспечения требуемой обратной связи. И вот тут-то и растёт осознанность по мере того, сколько из этих знаков попадает в поле внимания практикующего и насколько адекватно они им интерпретируются. В этом и заключается основная суть метода использования интегральных практик для роста осознанности.

\section{ЛИТЕРАТУРА}

1. Аллахвердов В.М. Методологическое путешествие по океану бессознательного к таинственному острову сознания. [Текст] / В.М. Аллахвердов. - СПб.: Изд-во «Речь», 2003. - 368.

2. Аллахвердов В.М. Опыт теоретической психологии. [Текст] / В.М. Аллахвердов . СПб.: Изд-во «Печатный двор», 1993. - 325 с.

3. Баранцев Р.Г. Понятия - Образы - Символы. Источник: http://www.trinitas.ru/rus/doc/0019/d01/00190005.htm

4. Бахтияров 0.Г. Технологии свободы [Текст] / О.Г. Бахтияров. М.: РИПОЛ классик, 2015. - 304 с.

5. Бхагаван Шри Сатья Саи Баба. Истина в афоризмах / Бхагаван Шри Сатья Саи Баба; сост. Е. Богатых. - 4-е изд. - М.: Амрита, 2012 -112 с.

6. Гендель М. Космоконцепция розенкрейцеров или мистическое христианство. - М.: Литан. 2004. - 560 с.

7. Ефремова Т.Ф. Новый толково-словообразовательный словарь русского языка [Текст] / Т.Ф. Ефремова. - М.: Изд-во Дрофа, Русский язык, 2000. - 1233 с.

8. Кришнамурти Дж. Немедленно измениться [Электронный ресурс]. Кришнамурти Дж. Немедленно измениться. - Режим доступа: http://www.rulit.me/ books/nemedlenno-izmenitsya-read-146111-1.html.

9. Лама Анагарика Говинда. Психология раннего буддизма. Санкт-Петербург: Изд-во «Андреев и сыновья», 1993, - с1-129.

10. Лествичник И. Лествица или Скрижали Духовные. [Электронный ресурс]. Электронная библиотека Royallib.com. - Режим доступа: http://royallib.com/ read/lestvichnik_ioann/lestvitsa_ili_skrigali_duhovnie.html\#0.

11. Мадджхима Никая. Ганакамоггалана сутта. [Электронный ресурс]. Указатель сутт. - Режим доступа: http://dhamma.ru/canon/mn/mn107.htm.

12. Махасатипаттхана сутта: большая сутта об основах памятования. [Электронный ресурс] Дигха Никая. - Режим доступа: http://www.theravada.ru/ Teaching/ Canon/Suttanta/ Texts/dn22-mahasatipatthansa-sutta-01-ivahnenko.htm.

13. Налимов В.В. Вероятностная модель языка. - М.: Наука 1979. - 270 с.

14. Насыров И.Р. Духовная практика в исламском мистицизме (суфизме): альтернатива откровению или имитация [Текст] / И.Р. Насыров // Философский журнал. - 2009. - № 2. - С. 49-63.

15. Пенман Д., Уильямс М. Осознанность. Как обрести гармонию в нашем безумном мире [Текст] / Д. Пенман, М. Уильямс. - М.: Манн, Иванов, Фербер, 2014. -46 c.

16. Пенроуз Р. Тени разума: в поисках науки о сознании. [Текст] / Пенроуз Р. - Москва-Ижевск: Институт компьютерных исследований, 2005. - 688 с.

17. Священная книга Тота. Великие арканы Таро. Абсолютные Начала Синтетической Философии Эзотеризма. Опыт комментария Владимира Шмакова. Киев: «София», 1993. - 510 с.

18. Тендзин Вангьял Ринпоче Тибетская йога сна и сновидений [Текст] Тибетская йога сна и сновидений. - Режим доступа: http://www.theosophy.ru/lib/twyoga.htm.

19. Уилбер К. Интегральная духовность. Новая роль религии в современном и постсовременном мире [Текст] / К. Уилбер. - М.: Ориенталия, 2013. - 520 с.

20. Уилбер К. Око духа: Интегральное видение для слегка свихнувшегося мира/ К. Уилбер /Пер с англ. В. Самойлова под ред. А. Киселева. - М.: 000 «Издательство АСТ» и др., 2002.- 476. [4] с. - (Тексты трансперсональной психологии).

21. Уилбер К., Паттен Т., Леонард А., Морелли М. Практика нтегральной жизни. Модель физического здоровья, эмоционального баланса, умственной ясности и духовного пробуждения для двадцать первого века. Электронное издание. Электронный ресурс www.ipraktik.ru 2014.

22. Уилсон Роберт Антон. Психология эволюции/пер. с англ. - М.: 000 Издательство «София», 2008. - 304 с.

23. Успенский П.Д. Психология возможной эволюции человека; Космология возможной эволюции человека Пер. с англ. - СПб.: ИД «ВЕСЬ», 2001. - 192 с., ил.

24. Хант Г. 0 природе сознания [Текст] / Г. Хант. - М.: Изд-во: Институт трансперсональной психологии, 2004. - 560 с. 
25. Хисматулин А.А. Суфизм [Текст] / А.А. Хисматулин. - Спб.: «Петербургское востоковедение», 1999. - 272 с.

26. Шри Ауробиндо. Собрание сочинений. Т.1. Биография. Глоссарий Пер. с англ. - СПб.: Издательство «Адити», 1998. - 571 с.

27. Bray S., Phllipson P. Geshtalt and Awareness [Текст] / S. Bray, P. Phllipson // Psychotherapy. - 2003. - № 3. - C. 56-67.

28. Brown K.W., Ryan R.M. The Benefits of Being Present: Mindfulness and Its Role in Psychological Well-Being [Tekct] / K.W. Brown, R.M. Ryan // Journal of Personality and Social Psychology Copyright. - 2003. - №4. P. 822-848.

() Непомнящий Анатолий Владимирович (pibgtsu@mail.ru), Хайбулина Эльвира Ильясовна (msgosh12@yandex.ru).

Журнал «Современная наука: актуальные проблемы теории и практики»

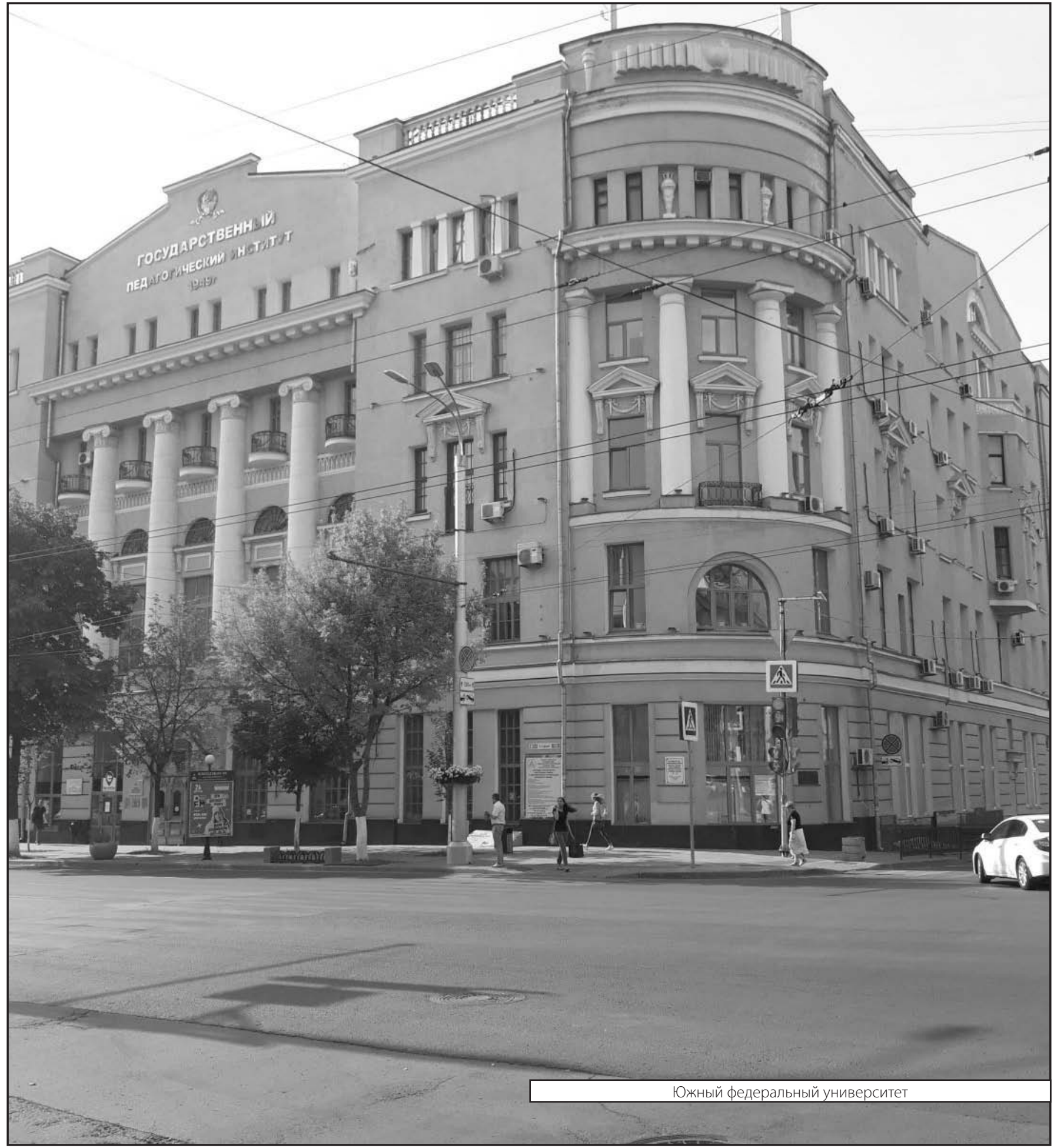

